\section{Occultations of Stars by the Moon}

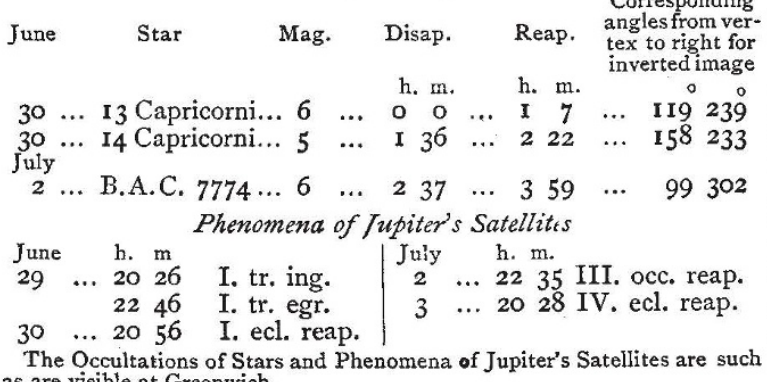
as are visible at Greenwich

July 3, 23h.-Sun at greatest distance from the Earth, the distance being one-sixtieth part greater than the mean distance.

\section{GEOGRAPHICAL NOTES}

THE Royal Geographical Society have decided to send out another African expedition. This time the region to be explored is one of more than usual interest, and the method of procedure will be considerably different from that which has been hitherto usually followed. We have had many lines run through Africa in all directions, and what is now needed is the leisurely study of the continent in detail. This is what will be done by the expedition which will leave England in August next, under Mr. J. T. Last, who, as a lay agent of the Church Missionary Society, has done admirable work in the Zanzibar interior. Mr. Last, after making up his caravan at Zanzibar, will proceed south to Lindi, to the north of the mouth of the Rovuma River. Thence he will proceed to the confluence of the Rovuma and Lutende Rivers, and fix the longitude of the junction-an important geographical point not yet settled. He will then go on in a generally south-westerly direction, and, before reaching the north end of Lake Shirwa, turn southwards and make for the Namulli Hills, which, with other new features in this region, were discovered by Consul O'Neill in the end of I883. Here Mr. Last will establish himself and make a detailed study of the whole region in all its aspects. He will make a complete survey of the surrounding country, its topography, its people, its botany, economic products, climate, and languages. When this is completed Mr. Last will enter the valley of the Likugu River, which rises in the neighbourhood of these hills, and follow it down to the coast of Quizungu, whence he will travel south to Quilimane or north to Angoche, and thence to Mozambique. Mr. Last will make a special point of collecting all possible information concerning the country he passes through, its changes ; its people, their customs, languages, \&c. ; the climate, its sanitary conditions, and its suitability for the introduction of European and other economic plants.

THE last number of Petermann's Mittheilungen contains the conclusion of Herr Schunke's account of Kaffraria and the eastern borderlands of Cape Colony; the Panama Canal, with a map, by the Editor ; the German possessions on the Slave coast, also with a map, by Herr Langhans ; the latest explorations in Costa Rica, by Dr. Polakowsky. This last is specially interesting. It is a continuation of a paper, published two years ago, and describes ten additional journeys to various parts of Costa Rica by Dr. Thiel the bishop. It is unfortunate for science that this ecclesiastic, whose energy in educating his flock and whose thirst for scientific investigation are alike remarkable, should have been expelled by the Costa Rican Government, and that in such haste that he was compelled to leave behind him all his journals, collections, scientific observations, \&c. He travelled and lived much amongst the various tribes of Indians, and studied their dialects, the antiquities, and ethnology of the country. $\mathrm{He}$ is at present visiting the eastern coasts of Nicaragua and Honduras in order to collect Indian antiquities and the remnants of Indian languages. The same paper also contains a report of a journey in Costa Rica by Padre Fernandez.

A CORRESPONDENT writes to Ausland from Santiago to correct a mistake as to a reported discovery of a glacier in Chile. The glacier in question is called the Ada glacier, and occupies the upper end of the Cajon de los Cipreses, a branch of the valley of Cachapual. In a note which appeared in the fourth number of Ausland this year and was copied from the Proceedings of the Royal Geographical Society, the discovery of this glacier was attributed to Dr. Güssfeldt. Some years previously the same discovery had been ascribed to Mr. Charles Wiener. The fact is, the correspondent states, the glacier has been known to the visitors to the baths of Cauquenes for the last twenty years at least. MM. Wiener and Güssfeldt, like other visitors to the baths, had had their attention called to it, and each in turn was consequently credited with its discovery.

THE French Minister of Public Instruction has published a report which he has received from $M$. Chaffanjon, a professor in Guadeloupe, giving an account of his mission on the Orinoco. In order to investigate fully the hydrography of the river he has often found it necessary to travel far away from the banks on both sides, and he has thus been able to survey the former beds. $\mathrm{He}$ has also obtained the materials for a geological map of the region and for a description of the phenomena attending the formation of this part of the earth's crust. Hitherto we have had only vague ideas respecting the Indian races, because they were without history or ancient remains. Prof. Chaffanjon has discovered in five different places inscriptions and pictures in granite, which he has carefully copied. $\mathrm{He}$ has collected a crowd of ethnological objects amongst the Caribs, the Panaies, and the Mapoyes. He hopes also to be able to fill certain gaps in the zoological and botanical collections in the Paris Museum. The report is accompanied by a sketch on a scale of $I$ to 660,000 of the course of the Orinoco between Caicara and Ciudad Bolivar, which gives a considerable number of names new to geography.

THE Berlin Geographical Society has decided to erect a monument at the burial place of the late Dr. Nachtigal, at Cape Palmas, and all Germans are invited to send contributions to the fund for this purpose.

\section{ELECTRICAL DEFINITIONS, NOMENCLATURE, AND NOTATION 1}

$W^{\text {ITH }}$ the rapid progress that has lately been made in electrical science and its applications, there has sprung up a new and fast-increasing class of practical electricians. These, partly from necessity and partly from well-meant respect, have adopted and applied the old terms and expressions which appeared suitable to their predecessors, as well as coined not a few new ones, until now their vocabulary is in considerable confusion, and, as all must admit, requires sifting and reform.

Nothing is more tantalising and perplexing than the different modes of expression and symbols used by different authors, and sometimes by the same author, to explain and interpret one and the same thing or result. All this might be avoided if an international system of definitions, nomenclature, and notation was agreed upon and legalised. The rapidity with which the new definitions of the ohm, ampere, and volt (issued and legalised last spring at Paris by the International Congress of Electricians) were universally adopted, shows this. These definitions should be still further extended to other electrical units. They should embrace a suitable system of notation, whereby electrician could represent in symbols and letters, terms, expressions, and formulæ of common occurrence, in a similar manner to that adopted by chemists in connection with chemical elements and their combinations. Last session the author promised a communication to the Society on this subject, and, being again reminded by the Secretary of his unfulfilled promise, he now submits a few of the more apparent instances where ambiguity or want of uniformity exists, with suggestions, in the hope that a discussion may follow, and that a Committee of this Society may be formed to consider and draw up a series of definitions, nomenclature, and notation that would be generally acceptable. The proposed Committee might then confer with the French Committee, also with a similar Committee appointed by the British Association, and, finally, this important question should be referred to the International Congress of Electricians, in order that they may legalise and issue their decisions in a similar manner to that adopted by them in the case of the ohm, the ampere, and the volt. Undoubtedly, if such a course were adopted, most beneficial results would accrue to all concerned.

Paper read before the Society of Telegraph Engineers and Electricians on May ${ }^{4} 4, x^{8} 85$, by Prof. Andrew Jamieson, C.E., F.R.S.E., Member. Principal, College of Science and Arts, Glasgow. 
Only last November M. Hospitalier brought this subject prominently before the International Society of Electricians at Paris, and strongly advocated an investigation, so that you shall no doubt have their support and concurrence. ${ }^{1}$

Examples.-(I) At the very outset students are perplexed by such different terms as "Ordinary ${ }^{2}$ or Static or Frictional or High-tension Electricity." One author will tell his readers or students : "For a long time the name Frictional Electricity was given to a group of phenomena produced by electrical charges. This is an improper expression, because friction is only one means for producing electrical charges." 3 Another says : "Static Electricity is, however, a misnomer : it has no existence : all the phenomena are due to static strains, but there is always a gradual loss called leakage, which is, however, the current due to the actual conductivity of all circuits, and every motion set up by so-called static electricity implies a transfer of energy and action occurring in a field of force set up in the form of strains in the particular inductive circuit in which the motions occur." $*$ A third objects to the word "tension " in respect to electricity, and points out that "all the phenomena observable in connection with so-called High-tension Electricity may be produced by electricity drawn from batteries or dynamos if the electromotive force or difference of potential is sufficiently increased." Would not the term "Electro-statics" be more suitable and comprehensive ? 5

(2) The old nomenclature "vitreous" and "resinous," as applied to substances which, when rubbed by certain other substances, produce opposite electrical properties, and the scholastic one and two fluid theories based upon these effects, should be discarded for the more comprehensive modern theory of electric polarity of molecules or continuous particles, expressed by "positive" and "negative," or by the algebraical signs $(+)$ and $(-)$.

(3) "'Electrics," “dielectrics," “ non-conductors," “ insulators," and "isolators" are terms used by different writers to express a condition or behaviour of certain materials with respect to electricity, in contradistinction to the terms "non-electrics" or "conductors" as applied to other materials. The words " electrics," "non-conductors," and " non-electrics" are, strictly speaking, meaningless, because all materials may be termed electrics and all conductors, only differing in degree. The words "isolators" and "isolation" (from the French verb isoler, to isolate or separate) should give way to "insulators" and "insulation" as applied to substances which offer a comparatively greater resistance to electricity than semi or good conductors used in connection with the apparatus being referred to at the time.

The term " dielectric" 6 was first used by Faraday on finding that conduction was effected by induction (of polarity from molecule to molecule), and is generally employed by practical electricians when speaking of the inductive capacity of the insulating material surrounding the conductor of leading wires or submarine cables, or that placed between the plates of a condenser. In this sense, viz., of a body transmitting electric induction, or capable of undergoing electric stress, and retaining the stressed condition, it is a very appropriate term to use.

¿ Communication faite à la Société Internationale des Électriciens, le 5 Novembre, 1884 , par M. E. Hospitalier sur L'Unité de Définitions, Conventions, Notations, et Symboles Électriques (vide L'Electricien, I5 Décembre, $\times 884$ ).

"Sur la proposition du Président, l'assemblée décide qu'une Commission spéciale sera nommée à l'effet de rechercher les meilleures méthodes à adopte pour les notations électriques et de codifier ces notations.

"M. le Président propose, au nom du Bureau, d'appeler à faire partie de la Commission des notations électriquez-

"MM. Ed. Becquere!

E. E. Blavier

Marie-Davy

Tresca

Maurice Lévy

G. Lippman

Félix Lucas

Mercadier

M. V. Williot.

"L'assemblée adopte cette liste à l'unanimité,"

2 The term used by Faraday. (See "Experimental Researches," by

3 "'Electrician's Pocket-Book," by E. Hospitalier, p. 5

4 "Electricity," second edition, by Sprague, p. 6, Art. 2o.

5 "Electricity and Magnetism," by Clerk Maxwell, vol. i., part r.

6 Faraday's "Experimental Researches." p. 364 . "I use the word dielectric to express that substance through or across which the electric forces are acting." (See also pp. 537,538 .)
(4) The term "accumulator" is the name given in several text-books to apparatus, such as the Leyden jar or condenser, for receiving and retaining quantities of electricity, but has been lately inappropriately applied to secondary batteries, which do not accumulate electricity.

(5) "Cascade," as applied to Leyden jars, should give way to "series."

(6) "Tension" I " potential," and "electro-motive force," are terms which, when variously and indiscriminately applied, have given rise to considerable confusion, and a great deal of writing in trying to define them. If we consider "tension" as simply the stress put upon the current by the electro-motive force, and not in the sense that it used to be employed (for example: "Join up a battery or set of condensers for tension"), it might do very well if kept in its place; but it can easily be dispensed with. "Potential" is a word that has also given great trouble.

We find in Sprague's "Electricity" 2 no less than three pages devoted to an explanation of the different ways in which the words "tension" and "potential" are employed. Clerk Maxwell said: "The theory of electro-statics is greatly simplified by the introduction of this new conception of potential." "As soon as we pass from electro-statics to other departments of electrical science, we find that the conception of potential is no longer available, except when used in a restricted sense and under carefully-defined conditions." "In other parts of electrical science we have to deal with electro-motive force in cases where "potential ' and consequential 'potential difference' are words without meaning." Prof. Fleeming Jenkin, in his well-known textbook on electricity and magnetism, devotes twenty-six pages to "potential," and defines "unit difference of potential or electro-motive force in electro-static measure to exist between two points when the unit quantity of electricity in passing from one to the other will do the unit amount of work." "The property of producing a difference of potential may be said to be due to a peculiar force, to which force the name electro-motive force is given." "The words electro-motive force and difference of potential are used frequently one for the other, but they are not, strictly speaking, identical." "Electro-motive force is the more general term of the two, and includes difference of potential as one of its forms." "Potential " might well be reserved for electro-statics, and "electro-motive force" for electro-kinematics, or current electricity, and thus prevent confusion. The word "electric-pressure" has come into vogue lately, and strongly appeals to those of a mechanical turn of mind, seeing that the hydraulic simile of "head" or "pressure" is often brought forward to assist in explaining the terms "potential" and "electro-motive force."

(7) In magnetism we find the same want of uniformity exists. Take the case of a freely-suspended magnetised needle. The pole which turns towards the geographical north is variously called the " austral pole," "north pole," " north-seeking pole," marked pole," and is painted red by Sir Wm. Thomson, while Sir Wm. George Airy, Prof. Guthrie, and others paint it blue. It is sometimes indicated by French makers by the letter $A$, and by British by the letter $N$. The pole which turns towards the geographical south is correspondingly called the "boreal pole," "south pole," "south-seeking pole," "non-marked ;" painted blue by Thomson, and red by Airy, Guthrie, and others, and indicated by the letter $B$, or $S$. Such is the general doubt and diversity in regard to the nomenclature on this subject, that each author on magnetism considers it necessary to state at the outset which term and symbol he intends to apply. If once for all the pole which turns towards the north was termed the " north pole," painted blue, and indicated by the letter $N$, and the opposite pole was termed the "south pole," painted red, and indicated by the letter $S$, much vexation would be savel. The French terms "austral" and "boreal," with letters $A$ and $B$, should be obliterated. In this way the earth would have a unitormly recognised polarity, which would of course be opposite to that of the magnetised needle-in other words, the true north pole of the earth would be that situated near the geographical south pole. ${ }^{3}$

(8) Sailors and some writers on the mariner's compass call the angle which the magnetic meridian makes with the geographical meridian the "variation" of the compass, while electricians

I For a good definition of these terms, see "Electricity and Magnetism," by Clerk Maxwell, vol. i. p. 49 . 3 Sir Wm. Thomson calls the magnetic pole of the earth, situated near the geographical north, the "north pole," and the end of the magnetised paints it red 
call it the "declination." Variation is, properly speaking, the hourly, diurnal, annual or secular changes which occur in the value of the elements of terrestrial magnetism. This leads to great confusion and argument between the electricians and the officers of a telegraph steamer. The declination for each place is marked on the Admiralty charts. Sailors also speak of the "deviation" of a compass, meaning by that the local error due to the resultant of the quadrantal, semicircular, and heeling errors, \&c. It would be far better if they simply spoke of the "compass error," or angle which the meridian of their compass-needle makes with the true north and south magnetic bearings. This deviation or compass error arises from local magnetic influences. Sir William Thomson's well-known compass, when properly adjusted on board a ship, has no compass error, and therefore the only thing to guard against and correct for in the steering of a ship is the declination of the place where the ship may be at the time of observation. Of course, if the magnetism of the ship changes in the slightest, due to a change of cargo or position thereof (if of iron or steel), or due to buffeting the waves for some time on one course, a slight error will creep in, but the compass can be soon adjusted to the new condition of affairs, and the officers have therefore seldom to think of or even speak of " deviation " or " compass error."

(9) When we come to electricity generated by batteries, we find the expressions "galvanism," "voltaic electricity," "dynamic electricity," " electro-kinetics," "current electricity," 1 \&c., according to the fancy of the writer or speaker. Surely one name might suffice ; and certainly the older term "galvanism," and "voltaic electricity" might well be left to the past. The simple term "current electricity" seems to commend itself, as most of the effects in connectlon with this branch of the subject have reference to electricity as if it was in motion or distributing itself over a conductor.

(Io) "Density of current" and "intensity of current" often cause great confusion. "Density of current" should only be used in the case of electrolysis or electro-deposition of metals. Here it means the amperes per unit of surface of the cathoder. In electro-statics "surface density" or " electric density" means the quantity per unit area of surface. "Intensity" was used at one time in the same sense as "electro-motive force" is now, and therefore not so much out of place there ; but several writers, notably Prof. Silvanus Thompson, have thought fit to borrow the French term "intensité de courant" wholesale, instead of a translation thereof, and to symbolise it by the letter $I$. The literal translation of the French word intensité being strength or amount, therefore the expression "current strength," or simply "current," symbolised by $C$, is far preferable, for it conveys the correct meaning of the quantity in a given time. With a little pressure, French electricians would no doubt agree to the symbol $C$ instead of $I$, to promote uniformity. Then $I$ might be reserved for intensity of magnetism, where it suits very well.

I I. "Positive electrode," " $(+)$ terminal," “zincode," "anode," "positive pole," and " negative plate," severally used by different writers to designate that end of a cell, battery, or pile where the current leaves, and "negative electrode,", " ( $(-)$ terminal," "platinode," "kathode" or " cathode," "negative pole," "chlorous pole," "positive plate," where the current returns to or enters the same, requires revising and simplifying, more especially when we consider that the end plates of a battery are of opposite sign to their electrodes or terminals, and that the nomenclature is still further complicated when we come to consider secondary batteries or electrolysis by the terms " anion," "kation " or "cation," and "ions." Take, for example, the definition given by Sprague ${ }^{2}$ of "anode": "The positive electrode or pole of a baitery ; the wire or plate connected to the copper or other negative element of the battery ; the plate which leads the + current into a solution to be decom posed, and at which are set free the oxygen, acid radicals and all -ions (anions). ${ }^{3}$ In electro-metallurgy it is usually formed of the metal to be deposited, in which case it is called the soluble anode or pole" !!

I See Ferguson's "Electricity," second edition, by Prof. Blyth, p. r6 4 . The term "electro-kinematics" has been used by Clerk Maxwell to cover a large part of this subject, such as "electric current," "conduction," "resistance," "electro-motive force," "electrolysis,"

agnetism," by Clerk Maxwell, vol. i. part 2.)

3 See Faraday's "Experimental Researches" nitions of New Terms, where he very clearly articles 661 to 667 , on Defa:taches to the words "electrode," "anode," "cathode," "ions," "anion," "cation," \&c.
12. Again, we have the two different ways of graphically representing a battery

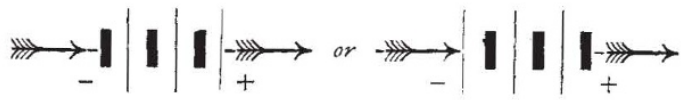

according to the whim or fancy of the writer. Practical submarine electricians were the first to use this very neat and handy way of representing a battery and its poles, and always adopted the former method, with the long thin vertical line for the plate where the current leaves, and the thick short line for the plate where the current returns to the battery. Why should this have been departed from? It is a mere arbitrary arrangement, but, being a most convenient symbol, it should be used in a uniform manner. Mr. John Munro proposes that the symbol for a secondary battery should be a modification of this, viz.,

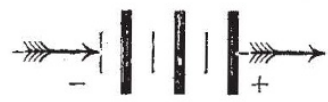

the current outside the cell proceeding from the long line to the short one.

13. " Parallel circuit," " multiple arc," " loop circuit," “ in loop," "derived circuit," "shunt circuit," are all expressions to signify pretty, much the same thing, where one expression, "shunt circuit," would do.

14. "Polarisation" is a term used in many different sensesfor example, the polarisation of battery plates, molecular polarisation due to electrification or magnetisation, polarisation of light due to magnetism, \&c., as in Dr. Kerr's experiments. Some reform is required here.

I5. Coming to telegraphy, telephony, and electric lighting, we find, as M. Hospitalier points out, "the words 'generator,' 'receiver,' 'transmitter,' and 'motor' are mixed up by different inventors, sometimes through ignorance, sometimes willingly." "A 'generator' is an apparatus which, receiving energy of a certain nature, produces an energy of another nature, and it borrows its name from the nature of the energy which it generates. A 'receiver' is an apparatus analogous to the generator, but it borrows its name from the energy which it receives." "A given apparatus is at once a generator and receiver-for example, an electric motor is a generator of mechanical energy and a receiver of electrical energy." "The name 'transmitter' ought to be reserved for an apparatus which, receiving an energy of a certain kind, produces or brings into play an energy of the same kind or of the same form." For example, a relay on a telegraph system, or induction coils as used on a trunk telephone line with several subscribers' lines at each end, or in electric lighting on the Gaulard and Gibbs' system, lately tried in London. Professor Silvanus Thompson uses the phrase "Dynamo-electric machinery" in the most general etymological sense of the term, as meaning machinery for converting the energy of mechanical motion into the energy of electric currents, or vice versâ, excepting such induction machines as Holtz, Voss, \&c. He thinks this reduces the ambiguity to a minimum, and leaves the word "motor" to be applied, if desired, to the steam-engine, water wheel, \&c., from which the mechanical motion is derived. The terms "magneto-clectric machine," as applied to a dynamo fitted with permanent field-magnets, and "electro-magnetic machine" to a series, separately-excited, shunt, or compoundwound dynamo (generator or receiver) are very handy expressions, and should not be discarded.

I6. We have dealt hitherto chiefly with definitions and nomenclature, and have given a few examples : others will occur to every member present. We now come to abbreviations and notation with symbols. The want of uniformity here, and the need for systematising, is still more obvious, but perhaps more difficult to accomplish. Every one admits the great advantage in being able to write down the symbols for chemical elements and their actions and reactions one with the other in the form of simple equations, which any one may comprehend who knows the subject, without a detailed description of what each letter or symbol stands for. Electricians should not rest satisfied until they are supplied with a similar universally-accepted notation, whereby electrical phenomena and actions may be similarly treated. The author submits a sample of what he considers would be useful in this respect. Many of them are taken from Munro and Jamieson's "Pocket-book of Electrical Formulæ," where an effort was made to use the same notation and abbre- 
viations throughout, except in such cases as that of quoting direct from some other author.

It will be observed in this list that in most cases the first English or Greek Ietter of the word has been used. Those relating to the metric system have been copied from the French edition of Hospitalier's "Electrician's Pocket-book," which are no doubt copied from the list decided upon by the International Commission on the Metre, with a few omissions and additions by the author.

The Greek letters $\pi, \mu, \epsilon$ are universally adopted $-\pi$ for the ratio of the circumference of a circle to its diameter, $\mu$ for the coefficient of friction, and $\epsilon$ for the base of Napierian logarithms.

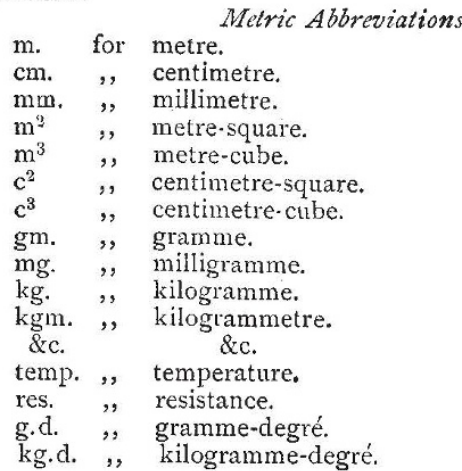

El:ctrical Abbreviations, Notation, and Symbols

When a capital letter is used for the symbol, then small capitals or italics with suffixes, I, 2, 3, \&c., may be used for parts making up a whole. For example-L for length, $\mathrm{L}_{1}, \mathrm{~L}_{2}, \mathrm{~L}_{3}$, $\& c$, or $l_{1}, l_{2}, l_{3}$, for different lengths, or parts of $\mathbf{L}$.

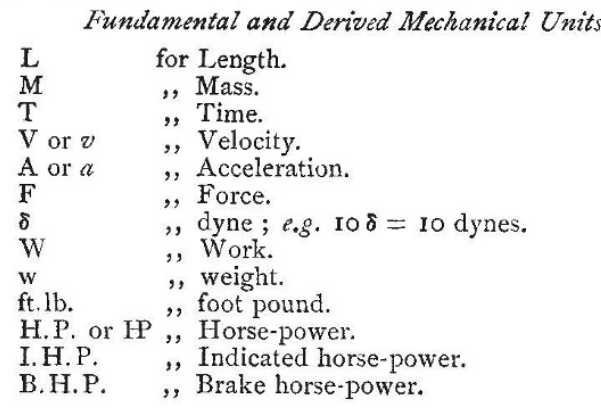

Other Common Symbols allied to Mechanical Work

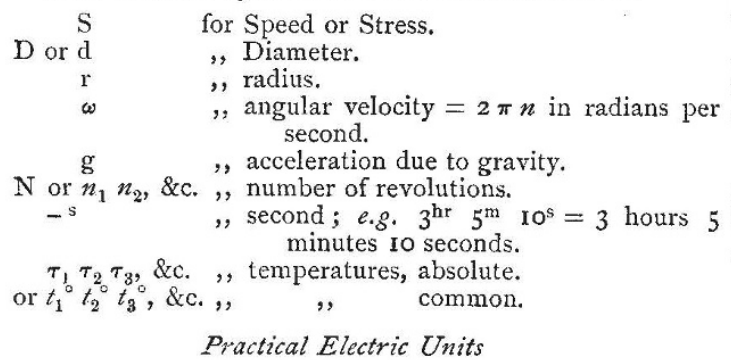

The astronomical method of putting the small letters above the line of the figures, as in the case of the example $3^{\mathrm{br}} 5^{\mathrm{m}} \mathrm{IO}^{\mathrm{s}}$ ( 3 hours 5 minutes 10 seconds), has not been followed in the following examples, as mathematicians object to the system, the letters appearing as if they were powers. Neither will they readily agree to suffixes, as suffixes have been already adopted by them to distinguish between things of the same kind. The author has therefore written the distinguishing letters on a level with the figures: for example, $\mathrm{rO}_{\omega}$ stands for $\mathrm{Io}$ ohms (the methods $10^{\omega}$ and $10_{\omega}$ being both objectionable).

C.G.S. for centimetre, gramme, second.

R , Resistance.

$\rho \quad$, specific resistance. $\omega \quad$ for ohm; e.g. $1 \mathrm{IO}_{\omega}=10$ ohms.
$\Omega \quad$ ", megohm; e.g. IO $\Omega=$ IO megohms.
$\mathrm{C} \quad$ ", Current.

\section{Important Electrical Definitions}

A $\quad$, Amperes; e.g. IOA $=10$ amperes.

a " milliamperes; e.g. Io $x=$ Io milliamperes.

E , Electro-motive force, or E.M.F.

$\mathrm{v} \quad$, , volts ; e.g. IOV $=$ Io volts.

$\mathrm{K} \quad$, Capacity.

$\sigma \quad$, specific inductive capacity.

$\Phi \quad$, , farads ; e.g. IO $\Phi=$ Io farads.

$\phi \quad$ ", microfarads ; e.g. $10 \phi=10$ microfarads.

Q ", Quantity (coulombs)

P ", Power.

W ", Watts, or Watt power. ${ }^{1}$

W " "Work in Joules.

$\mathrm{H} \quad$," Heat in ,

J "Joule's equivalent $=42 \times 10^{6} \mathrm{ergs}$, or work $\mathrm{C}=\frac{\mathrm{E}}{\mathrm{R}}$ (Ohm's law). spent on $2405 \mathrm{gm}$. of $\mathrm{H}_{2} \mathrm{O}$ raised by $\mathrm{I}^{\circ}$ cent.

$\mathrm{E} \times \mathrm{C}=\mathrm{C}^{2} \mathrm{R}=\frac{\mathrm{E}^{2}}{\mathrm{R}}=\mathrm{W}^{\mathrm{P}}$ (Watt powers).

$\mathrm{ECT}=\mathrm{C}^{2} \mathrm{RT}=\frac{\mathrm{E}^{2} \mathrm{~T}}{\mathrm{R}}=\mathrm{E} \mathrm{Q}=\mathrm{W}$ (Joules).

$\begin{aligned} \frac{E C T}{J} & =\frac{C R T}{J}=\frac{E^{2} T}{J R}=\frac{E Q}{J}=\frac{W}{J} \\ & =W \times \cdot 2405=g . d . \text { or grammed }\end{aligned}$

$=\mathrm{W} \times \cdot 2405=$ g.d. or gramme degrees.

$z=$ Electro-chemical equivalent.

\section{Magnetism}

$\mathrm{N}$ for North pole of a magnet, painted red.

S ", South ", ," ", blue.

$m$ ", magnet strength (of pole) or quantity of magnetism.

$l$,, distance between the poles of a magnet.

M or $m l$ ", moment of a magnet.

$\mathfrak{3}$ or I , Intensity of magnetisation.

$s \quad$, cross section of a magnet.

$\mathrm{mp}$, magnetic potential.

$\mu$,", magnetic permeability.

$\kappa \quad$, , magnetic susceptibility.

$\mathrm{H}$ " Horizontal intensity of terrestrial magnetism

$\theta$ ", angle of deflection.

$d_{1} d_{2} d_{3}$ ", divisions deflection, as in mirror galvanometer. $r$ " radius (mean) of a coil or solenoid.

$n$ "number of anything; e.g. turns of wire in a coil or galvanometer.

Take Tangent Galvanometer Formulæ, as an example to illustrate the above :-

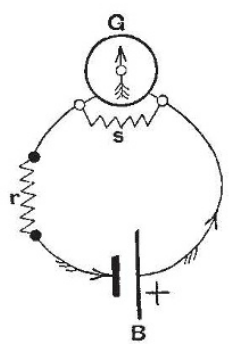

Current, $\mathrm{C}=\mathrm{H} \frac{r}{2 \pi n} \cdot \tan \theta$.

$\mathrm{G}$ for Galvanometer or galv. res.

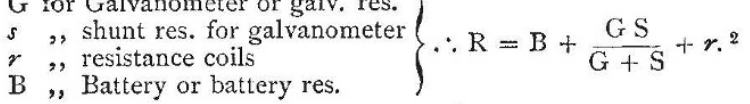

I By adopting the term "Watt power," there can be no doubt what a Watt means.

2 See Munro and Jamieson's "Electrical Pocket-book," p. 65. 


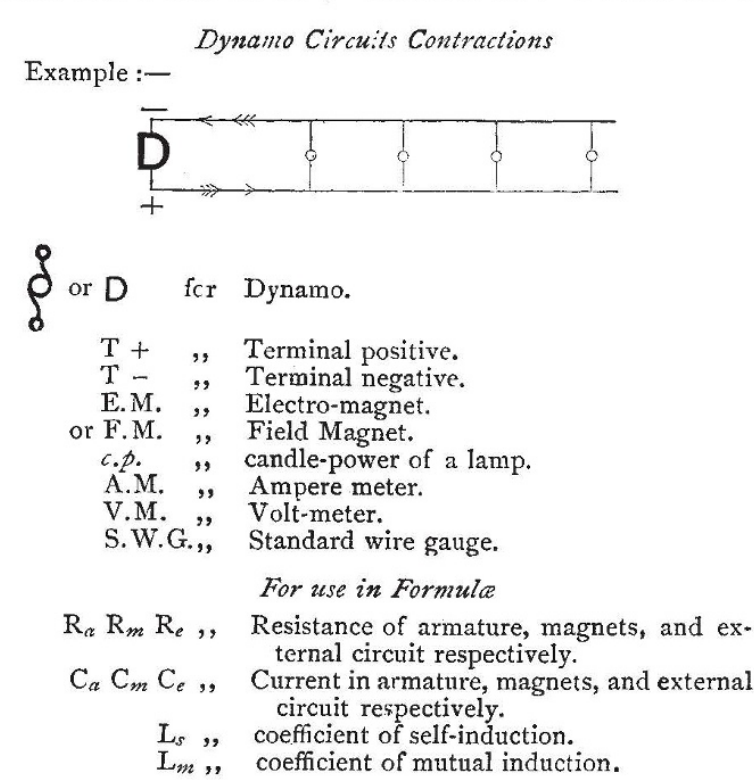

In the above notation the first letter of the most important words has been used wherever it was found practicable to do so, and the recurrence of the same letter under similar circumstances avoided as much as possible. In cases where no ambiguity can occur, such as $\mathrm{H}$ for the heat in Joules, and $\mathrm{H}$ for the horizontal intensity of the terrestrial magnetism; $m$ for metre, and $m$ for magnetic strength of pole; $\mathrm{V}$ for velocity, and $\mathrm{V}$ for volts, it will be observed that the same letters appear in each case.

M. Hospitalier, the Secretary for the French Committee on this subject, came over from Paris specially to take part in the discussion, and related what had already been done by him in Paris.

Prof. Forbes, Mr. John Munro, Prof. Ayrton, Dr. Fleming, Prof. Hughes, Prof. Silvanus Thompson, and others took part in the discussion, and generally agreed that a uniform system was much required. The paper, they said, had given a very fair start to this being accomplished.

The author replied that he was glad the Society had agreed so readily to form a thoroughly representative committee, and hoped that their work would be not only speedily accomplished but satisfactory to all concerned.

\section{THE JUBILEE OF THE STATISTICAL SOCIETY}

THE Statistical Society has been holding a series of meetings during the present week in celebration of the jubilee of its foundation. The meeting is really an International Congress of Statistics, some of the most eminent foreign statisticians being present as the guests of the Society ; among others Sig. Bodio, of Rome; MM. Keleti, Körösi, and Prof. Neumann-Spollart, of Buda-Pesth ; Prof. Levasseur and M. de Foville, of Paris Gen. F. A. Walker, of the United States, Gen. Liagre, and others. The meetings have been held in the theatre of London University, and several subjects of much statistical importance have been introduced for discussion. One of them was the claim of statistics to be considered as a science, discussed at some length in the address of the President, Sir Rawson W. Rawson. Statistics, as usually treated in this country, little more than the mere calculating of numbers, is a mere mechanical operation; but which, treated as some of the most eminent statists have treated it, as dealing with the structure of human society, then it certainly becomes amenable to scientific methods. Sir Rawson Rawson referred further to the want of organisation in the collection and publication of official statistics in this country, and rightly advocated reform in this respect. Among the other papers read on Monday were-a sketch of the history of the Society, by Dr. F. J. Mouat; "Statistical Developments, with special reference to Statistics as a Science," by Dr. W. A. Guy, F.R.S. ; and on "Statistics and their Enemies," by M. de Foville. One of the principal papers on Tuesday was by Mr. R. Giffen, on "Some General Uses of Statistical Knowledge," in which, among other things, he referred to the rapid increase of the population of Europe during the last century as compared with the increase in China and other Asiatic countries (except India) and in Africa. Should the present rate of European increase continue, the population of our continent in another century will be 1000 millions, whilst that of the United States would be 800 millions. Mr. Giffen maintained that the increase in Europe had been accompanied by a corresponding increase in the means of subsistence and improvement in the position of all classes.

Mr. J. S. Jeans read a paper "On Uniformity of Statistics." $\mathrm{He}$ held the chief desiderata required with a view to the improvement and co-ordination of the statistical work undertaken by different Government bureaux were: (I) an agreement as to the major facts necessary to be collected for each special department of statistics ; (2) uniformity in the processes by which these facts were got together; (3) co-ordination of the methods whereby the materials thus collected were systematised and made use of ; (4) the adoption, as far as possible, of the calendar year as the universal statistical period, so that when comparisons were made they should alway relate to the same dates ; $(5)$ the general adoption of the metrical system of weights, measures, and currency.

Herr Körösi spoke "On the Unıfication of Census Record Tables." The voluminous and polyglot census results of the world were, he found, practically non-comparable, and he proceeded to sketch a uniform scheme of record tables by which we should arrive at one bound at the highest aim of statistics-the possession of a uniform description of the different nations and of all mankind as regarded sex, age, civil state, illiteracy, occupations, \&c.

Mr. F. Y. Edgeworth, in a paper entitled "The Methods of Statistics," confined himself to the treatment of numerical means. He showed that if we take several means of phenomena belonging to one and the same class (e.g. statures of men), each mean derived from numerous observations, the set of values thus presented would in general /fulfil a certain simple mathematical law. The general formula involved a constant or coefficient peculiar to each class of phenomena, which must be discovered by experience. When this operation had been performed we had an apparatus for testing whether any given mean was or was not exceptional, indicative that the set of things of which the datum was the mean might ( (as compared with other phenomena of the same general class) be regarded as belonging to a distinct species. A pretty illustration of important principles was afforded by the statistics of a wasp's nest, "the image of trade which wasps entering and issuing from their nest present." It appeared that the exports and imports of this miniature commerce fluctuated with mathematical regularity. As further illustrations of the variety of interests amenable to the general law, he adducer the attendance of the members of a club at a talle d'hote, and the frequency of dactyls in the Latin hexameter. The conditions postulated by the Calculus of Probabilities were particularly well exemplified by the fluctuations of the Virgilian rhythm. In conclusion, he alluded to the simpler methods of statistics, and maintained that the mathematical, as compared with the more elementary, organon could produce the same effect with less trouble, or, with the same trouble, greater effect.

M. Emile Levasseur, Member of the Institute and Professor at the College of France, initiated a discussion on the graphic method applied to statistics, exhibiting diagrams and cartograms or statistical maps illustrating his views. Prof. Marshall, of Cambridge, who followed, advocated the use of a standard gauge for historical curves in order to simplify references to the graphic method of statistics, and pointed out dangers in the employment of curves arising from their deceptive appearance to the untrained eye. He suggested a ready means of testing the values of curves under comparison.

Yesterday was entirely occupied by a conference and discussion on the subject of an International Statistical Institute, the establishment of which was virtually agreed to.

\section{UNIVERSITY AND EDUCATIONAL INTELLIGENCE}

CAmbridge. - At the annual election at St. John's College on June 22, the following awards were made to students of Mathematics, Natural Science, and Medicine :-

Foundation Scholarships.-Mathematics: Love, Fletcher 